\title{
A tribute to
}

\section{J.J.Thomson}

Henk Kubbinga - University of Groningen (The Netherlands) - DOI: 10.1051/epn/2011501

\begin{abstract}
Europe was thrilled by a new instrument, or was it just a gadget? The gas discharge tube was invented by Johann Geissler (1857). Very soon it became a British plaything: with his demonstrations William Crookes impressed the Royal Society (1878) and the British Association for the Advancement of Science (1879). The new Cavendish Professor for Experimental Physics, at Cambridge, Joseph John Thomson —simply J.J. for colleagues and posterity-took over.
\end{abstract}

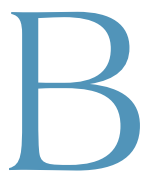

orn near Manchester to a bookseller-antiquarian in 1856, Joseph John Thomson was expected to become an engineer. However, at Owens College, Manchester, his attention

after a while shifted to mathematics. The shift was a conscious one, since mathematics was the only way to get an endowed entrance at Cambridge, more particularly at Trinity College. In 1880, then, Thomson passed the final examination, second in line, after Joseph Larmor. Through his Treatise on Electricity and Magnetism, Clerk Maxwell, whose tragic death was still in the air,

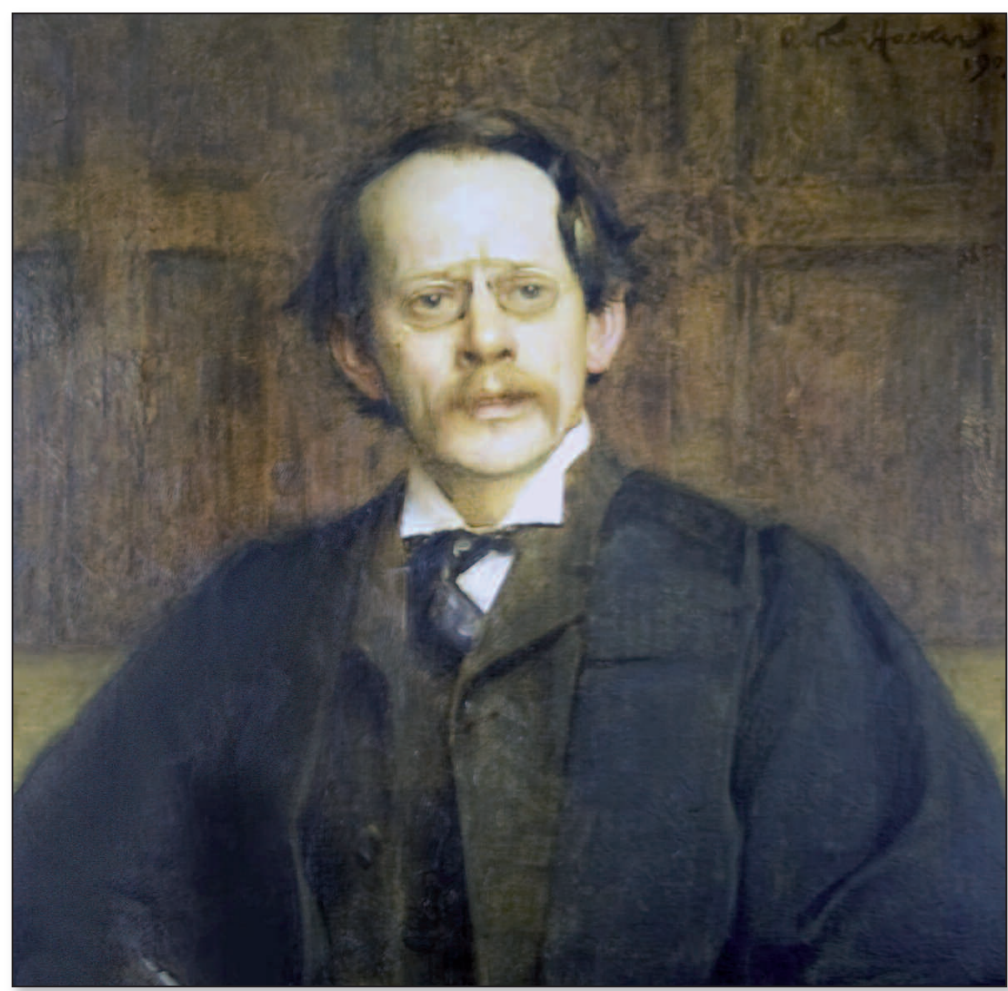

reigned supreme, together with Stokes and the future Lord Kelvin. Physics still was essentially mathematical physics. In this context a prize-winning essay by Thomson was published as A Treatise on the Motion of Vortex Rings (1883). In it he inter alia described, following his distinguished namesake, several experiments with magnetized needles carried by cork slices on top of a water surface, grouping around a large magnet's pole at the centre. Other topics that occupied Thomson derived from Maxwell's work: the nature of potential energy in mechanics and its relation to the kinetic energy of systems, and electrodynamics. In both, the use of mechanical models - to lead both the imagination and the mathematical analysis-was of paramount importance.

Through a series of fortunate coincidences, Thomson became short-listed when, in 1884, Rayleigh, the successor of Maxwell, moved on to the Royal Institution, London. He was nominated indeed and from the very outset, the discharge tubes with their fairy-like phenomena became his favourite research subject.

\section{Discharge tubes; corpuscles}

In the late 1850's the instrument-maker Johann Geissler of Bonn University, already a celebrity for his thermometers and his air pumps based on mercury, had equipped an evacuated tube with platinum electrodes. With the help of a recent invention, the Rühmkorffinductor, he produced rapid successions of sparks through rarefied air and other gases. The set-up resembled Michael Faraday's when he studied the conductivity of various media. Hence the idea that it was a matter of electrolysis, this time of gases and accompanied by fascinating light effects that could be steered by a magnet. In 1875, a new invention-this 
time one by William Crookes, London-brought the discharge tube back into focus. The apparatus in question became known as the radiometer; it consisted of an evacuated bulb with a set of vanes, mounted on a spindle, which started to spin as soon as it was exposed to light. The experiment suggested that external light could have a mechanical effect, perhaps mediated by rest-gas molecules. The surface of the cathode of the discharge tube, then, could be likened to the black sides of the vanes: in both cases it would be a matter of bouncing molecules. Gradually, however, the ever more appealing discharge tubes took the place of the radiometer. Crookes postulated a fourth-extremely rare-state of matter, in which charged molecules could manifest their mechanical power. In one of his contrivances, a wheel with spades started spinning along a railway in the direction of the anode, even braving gravity when kept slightly inclined: obvious mechanics, matter in motion driven by matter in motion.

Evacuated tubes with aluminium foil windows showed Heinrich Hertz (1892) that cathode rays could permeate such foils, a fact that stressed, from the British point of view, the tiny nature of the particles involved. How else might their free paths of some $5 \mathrm{~mm}$ in air be explained? Wilhelm Röntgen (Munich), in the autumn of 1895, noticed a secundary effect: the unexpected lighting up of remote fluorescent materials. Hendrik Lorentz (Leyden), then, made use of tiny particles-by now evidently subatomic moieties - to explain the broadening of the $\mathrm{NaD}$-line between the pole pieces of a strong electromagnet, as discovered by Zeeman (October 1896).

Cambridge-with Oxford living in splendid isolation, even in the UK-had been opened, in 1895, to the academic world at large and advanced students looking forward to do research flocked to the Cavendish Laboratory. Before long, the $\mathrm{PhD}$ system was introduced in order to create 'research doctors', as in the German and French academia. Among the first to be admitted was one Ernest Rutherford, from New Zealand; many would follow. With Hertz's stunning find as inspiration, Thomson set out to study both charge and mass of the 'electrified particles' that constituted the cathode rays. In a first attempt, he established their kinetic energy by measuring their heat effect on a copper-iron "thermoelectric couple", connected to a sensitive galvanometer: $n \cdot\left(1 / 2 m v^{2}\right)=W=$ kinetic energy of $n$ particles transformed into heat with $n \cdot e=Q=$ quantity of electricity involved. A magnetic field of strength $H$ causes the 'electrified particles' to adopt a circular trajectory of radius $r$. That radius varies, naturally, directly as the particle's mass $\mathrm{m}$ and its velocity $v$, and inversely as the particle's charge $e$ and the magnetic field strength $H$. Hence $m v / e$ $=H r$, or $m v=e H r$, which may be substituted in the expression for $W$ and leads to $m / e=1 / 2(H r)^{2} \cdot(Q / W)$. The ratio $W / Q$ was measured first $\left(=8,7 \cdot 10^{11}\right.$ e.s.u. $)$;

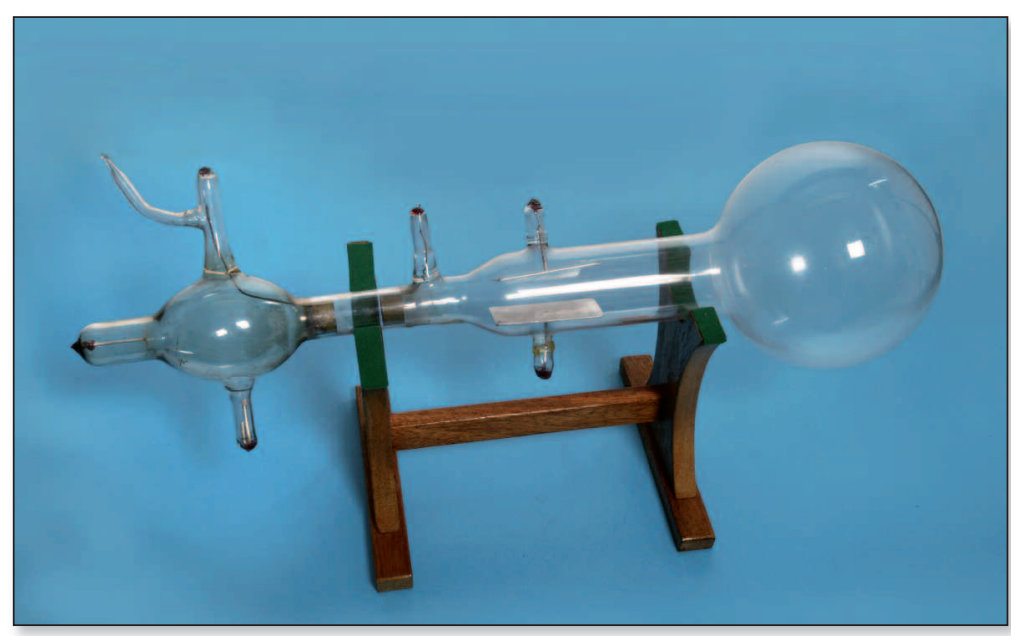

$r$ was calculated, next, from the path in the tube, a circle segment; $H$ was the known strength of the electromagnet. By varying $H$ and measuring $r$, Thomson established the product $\mathrm{Hr}$ ( $=287$ e.s.u.). Therefore $\mathrm{m} / \mathrm{e}$ $=1 / 2 \cdot(287)^{2} / 8,7 \cdot 10^{11}=4,7 \cdot 10^{-8}$ e.s.u. In a later experiment, which became a classic, Thomson combined the deviation in a magnetic field with that in an electric field. This led to $m / e=1,2 \cdot 10^{-7}$ e.s.u. Again, hydrogen and carbon dioxide tubes gave the same results, while the metal of the cathode ( $\mathrm{Al}, \mathrm{Pt})$ did not matter, so there were really fundamental particles at stake; From electrolysis data, the ratio $m / e$ of hydrogen ions was already known to be $10^{-4}$. Assuming the charges involved to be equal, Thomson's 'electrified particles' had to be some 1000 times lighter. His experiments thus confirmed the earlier results, as to the tiny nature of those particles.

The combined effect of magnetic and electric fields appeared to be the most practical way. The quality of the vacuum, then, proved essential: to confirm that there was indeed an electric field effect-that is, without conduction-the rest pressure had to be lowered further significantly. Figure 2 shows Thomson's well-known tube. The tube in question was blown-by Ebeneezer Everett, Thomson's cherished virtuoso [2] from soft glass imported from Germany, known already for its lightgreen fluorescence when exposed to cathode rays. The logic was incontrovertible, the calculation refreshingly simple and straight forward.

\section{Corpuscular matter}

Thomson became convinced of the elementary nature of his corpuscles. Though most physicists gradually adopted the term 'electron'-proposed by Stoney in 1894-, Thomson did not give in for at least a decade. Indeed, the term corpuscle seemed consecrated by Thomson's being awarded the Nobel Prize of 1906. The next year, the laureate published his magnum opus, entitled The corpuscular theory of matter. As to terminology, apart from some stubbornness, there might be some piety in the game, scientific piety, that is: after all, $\triangle$ FIG. 2:

Thomson's (presumably original) discharge tube (length: $40 \mathrm{~cm}$; cross-section bulb: $11 \mathrm{~cm}$ ). The pierced anode(s), on the left, are in brass, the cathode and the condenser plates in aluminium; the latters' positions have suffered. The electrode on the lower-left was probably used to check the vacuum quality. Photo: Kelvin Fagan, Cavendish Laboratory. 
V FIG. 3:

Magnetic

needlespushed through small corks-

floating on a

water surface

under the

influence of an

electromagnet:

four needles

constitute a

square. Five

needles

would form a

pentagon. In case

of six needles,

one of these is

dragged to the

center, the other

five forming a

pentagon (from

ref. [4], p.111)
- no one less than Robert Boyle had ventured to propose in his days, a 'corpuscular philosophy' of similar stature (1661). For Thomson, then, the physico-chemical atom consisted of equal amounts of positive and negative electricity. The positive electricity was considered as a "sphere of uniform density" in which the corpuscles were embedded, like the raisins in a plumpudding. His earlier study of the ordering of corked magnetic needles, was helpful to visualize how those corpuscles could form stable arrangements (Figure 3).

\section{Metals and their conductivity}

About 1900 metals were conceived of as ordered wholes of positive charges through which the 'corpuscles' diffused like the molecules in a gas. Paul Drude (1863-1906) was among the first proponents; he was followed by Hendrik Lorentz. Long ago, for metals, the ratio of the electric to the thermal conductivity, $\kappa / \sigma$, had been found to be a constant, a law called after Wiedemann and Franz (1853). Drude succeeded in deducing that law from the molecular gas model Where he posited a mean velocity, Lorentz saw a normal distribution in the spirit of Maxwell and Boltzmann (1905). A large amount of generally acknowledged phenomena now made sense in the new light: from the discharge tube phenomena-through the contact potential of bimetals and the Hall effectto the liberation of corpuscles either by heating or by
UV-light or X-rays. Thomson was enthused: in his monograph of 1907 he calculated the speed of his corpuscles in the metallic 'void' from the mass ratio with the hydrogen atom to be about $100 \mathrm{~km} \cdot \mathrm{sec}^{-1}$ [4].

\section{Positive (Canal) rays; their parabolic 'spectral' lines (1912)}

Thomson's attention shifted to what he used to call 'positive rays': positive ions, that hit the cathode, moving upstream with respect to the corpuscles. These rays had been noticed for the first time in the 1880's by Eugen Goldstein (Potsdam); he had called them 'Kanalstrahlen' The ions, too, proved to be sensitive to electric and magnetic fields. However, where the corpuscles always showed one and the same trajectory-photographed by Thomson already in 1896-, the ions manifested distinct paths, which strongly suggested that they varied as to their mass. A whole series of atomic and complex ions could be identified in this way, since 1910 by photographic means. In 1912, then, Thomson applied his specialty, viz. the combination of magnetic and electric fields, to a beam of neon ions, which revealed the existence of two kinds of equally charged neon ions. They were dubbed isotopes by Frederick Soddy. It was Thomson's assistant Francis Aston, who, after the Great War, developed the mass-spectrograph and proved him right. It was the time that J.J. was nominated 'master' of Trinity College, in scientific practice Cambridge's most prestigious emeritus status. [

\section{Acknowledgment}

The author is indebted to Richard Friend, the actual Cavendish Professor of Physics, and Malcolm Longair, formerly Head of the Cavendish Laboratory (1991-2005) for their generous hospitality and to Kelvin Fagan for the especially made photograph of Thomson's tube. Courtesy photographs: Cavendish Laboratory, Cambridge.

\section{About the author}

Henk Kubbinga is a historian of science at the University of Groningen and member of the EPS History of Physics Group. His work-in-progress concerns The Collected Papers of Frits Zernike (1888-1966), of which volumes I and II are forthcoming (Groningen University Press).

\section{Notes and references}

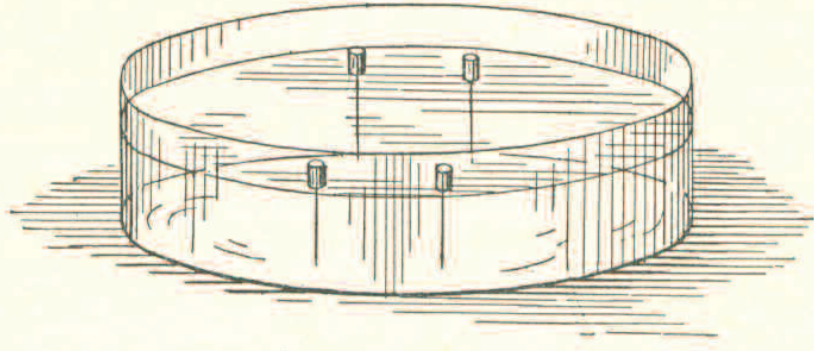

[1] W. Crookes, Philosophical Transactions 170 (1879) 135

[2] It was typically Thomson who, when Everett died in 1933, wrote an obituary of his truefull righthand for well over forty years; see Nature 132 (1933) 774

[3] J.J. Thomson, Philosophical Magazine 44 (1897) 293

[4] J.J. Thomson, The corpuscular theory of matter, London: Constable, 1907 